Rev. Int. Contam. Ambie. 36 (4) 957-966, 2020

https://doi.org/10.20937/RICA.53711

\title{
PATOTIPOS Y RESISTENCIA A ANTIBIÓTICOS DE Escherichia coli EN AGUA RESIDUAL
}

Pathotypes and antibiotic resistance of Escherichia coli in residual water

\author{
Ángeles MARTÍNEZ-ORGÁNIZ1 ${ }^{1}$, Ulises GARZA-RAMOS², María L. SAMPEDRO-ROSAS ${ }^{1}$, \\ Justiniano GONZÁLEZ-GONZÁLEZ ${ }^{1}$, Getzemany NAVA-FAUSTINO ${ }^{3}$ and Jeiry TORIBIO-JIMÉNEZ ${ }^{3 *}$
}

${ }^{1}$ Centro de Ciencias de Desarrollo Regional, Universidad Autónoma de Guerrero, Pino s/n, Col. El Roble, 39640 Acapulco, Guerrero, México.

${ }^{2}$ Instituto Nacional de Salud Pública, Av. Universidad 655, Col. Santa María Ahuacatitlán, 62100 Cuernavaca, Morelos, México.

${ }^{3}$ Laboratorio de Microbiología Molecular y Biotecnología Ambiental, Facultad de Ciencias Químicas, Universidad Autónoma de Guerrero, Col. Haciendita, 39087 Chilpancingo, Guerrero, México.

*Autora para correspondencia: jeiryjimenez2014@gmail.com

(Recibido: septiembre de 2019; aceptado: abril de 2020)

Palabras clave: efluente, resistencia bacteriana, agua residual.

\section{RESUMEN}

La contaminación del agua es un problema ambiental grave. En una planta de tratamiento de agua residual (PTAR) en México se evaluó la presencia de coliformes fecales totales y de Escherichia coli, la prevalencia de patotipos diarreicos y los perfiles de resistencia a los antibióticos en las diferentes etapas del tratamiento. Se realizaron tres muestreos compuestos para evaluar la presencia de $E$. coli con los parámetros físicos y químicos establecidos en la Norma Oficial Mexicana NOM-001-SEMARNAT-1996. Se seleccionaron 57 cepas de las diferentes etapas del proceso y se determinó el patotipo de E. Coli por reacción en cadena de polimerasa múltiplex: enteropatógena (EPEC), enterotoxigénica (ETEC), enteroinvasiva (EIEC), enteroagregativa (EAEC), enterohemorrágica (EHEC) y de adherencia difusa (DAEC); asimismo, se determinó su resistencia por el método de Kirby Bauer. Los resultados muestran una eficiencia de remoción del $95.4 \%$, con base en la demanda química de oxígeno $\left(\mathrm{DBO}_{5}\right)$. Los coliformes y E. coli son mayores en el influente. La frecuencia total de patotipos fue del $39 \%(22 / 57)$ de EIEC, $30 \%$ (17/57) de ETEC y $15.5 \%$ (9/57) de DAEC y EPEC. Respecto de la distribución, se detectó un $39 \%$ de ETEC en el influente, $50 \%$ de EIEC antes de la desinfección, $100 \%$ de EIEC después de la desinfección y un $43 \%$ de ETEC en el efluente. Todas las cepas muestran baja resistencia a los antibióticos. La eficiencia de remoción de la PTAR, con base en el $\mathrm{DBO}_{5}$, es alta y cumple con las normas ambientales, sin embargo, la presencia de patotipos diarreicos en el efluente impacta negativamente al ambiente y a la salud pública.

Key words: effluent, bacterial resistance, waste water.

\begin{abstract}
Water pollution is a serious environmental problem. We analyzed the presence of total fecal coliforms and Escherichia coli, the prevalence of diarrheal pathotypes, and the
\end{abstract}


profiles of antibiotic resistance at different stages. Three composite samples from a wastewater treatment plant (WWTP) in Mexico were analyzed for the presence $E$. coli with the physical and chemical parameters established in the Mexican Official Standard NOM-001-SEMARNAT-1996. Fifty seven strains were selected from the different stages of the process, and the following pathotypes were determined by multiplex polymerase chain reaction: enteropathogenic (EPEC), enterotoxigenic (ETEC), enteroinvasive (EIEC), enteroaggregative (EAEC), enterohemorrhagic (EHEC), and diffuse adherence (DAEC). Their resistance was assessed by the Kirby Bauer method. The results showed a removal efficiency of $95.4 \%$ based on the chemical oxygen demand (BOD5). Coliforms and E. coli were found to be higher in the influent. The total frequency of pathotypes was $39 \%$ (22/57) for EIEC, $30 \%(17 / 57)$ for ETEC, and $15.5 \%$ (9/57) for DAEC and EPEC. Regarding the distribution, 39\% of ETEC was detected in the influent, $50 \%$ of EIEC before disinfection, $100 \%$ of EIEC after disinfection and $43 \%$ of ETEC in the effluent.

\section{INTRODUCCIÓN}

La contaminación del agua es considerada un problema ambiental emergente que ocasiona efectos graves en la salud humana y a los ecosistemas (Huang et al. 2006, Kümmerer 2009a). Se estima que en 2025 más del $60 \%$ de la población mundial sufrirá problemas de escasez de este recurso; sin embargo, el desafío en la actualidad es tener agua potable, debido a que miles de millones de personas están expuestas a diversos contaminantes y patógenos transmitidos a través de su consumo. En el agua, las heces de humanos y animales son la principal fuente de coliformes $u$ otras bacterias patógenas, las cuales pueden dispersarse en el ambiente. Las plantas de tratamiento de aguas residuales (PTAR) son consideradas como una de las principales fuentes de contaminación por este tipo de contaminantes (US-EPA 2005, Ye y Zhang 2011, Novo et al. 2013). La ingestión de agua con restos fecales es la vía de transmisión más frecuente de enfermedades intestinales que afectan a las poblaciones vulnerables. En México, las enfermedades diarreicas ocupan uno de los primeros lugares en la morbilidad/mortalidad de niños menores de 5 años de edad y generan el $7.4 \%$ de la demanda de consulta en los servicios de salud y el $10 \%$ de las hospitalizaciones pediátricas (Franzolin et al. 2005). Entre los patógenos intestinales transmitidos por el agua, el más frecuente es la bacteria Escherichia coli, cuyos patotipos diarreicos son considerados un problema ambiental y de salud pública a nivel mundial (Sidhu y Toze 2009). Dichos patotipos de E. coli son: enteropatógena (EPEC), enterotoxigénica (ETEC), enteroinvasiva (EIEC), enteroagregativa (EAEC), enterohemorrágica (EHEC) y de adherencia difusa (DAEC) (Nataro y Kaper 1998, Weintraub 2007). La ETEC causa diarrea acuosa en niños y adultos
(Shaheen et al. 2004). En México, este patotipo se ha aislado en el $70 \%$ de los casos de brotes epidémicos y se asocia con zonas donde la higiene es precaria. La presencia de cepas patogénicas de E. coli en el agua residual se agrava por la capacidad de intercambiar genes de resistencia a los antibióticos a partir de mecanismos de transferencia horizontal.

El uso y abuso de antibióticos en la comunidad, hospitales, ganadería, veterinarias y agricultura ha generado que se dispersen y liberen en el medio acuático y lleguen a las PTAR, contribuyendo a la selección y diseminación de bacterias resistentes en el ambiente acuático (Davies y Davies 2010). La presencia de antibióticos en el ambiente y la resistencia bacteriana es una preocupación mundial (Rodríguez et al. 2006). A pesar de lo anterior, este fenómeno no se ha estudiado completamente en entornos ambientales (Martí et al. 2014). Diversos estudios han revelado que las concentraciones subinhibitorias de antibióticos reportadas en ambientes acuáticos (Kümmerer 2009a, b) pueden promover la resistencia bacteriana (Gullberg et al. 2011, Chow et al. 2015). Los residuos de diversos antibióticos son excretados a través de la orina y las heces (Kasprzyk-Hordern et al. 2008, Al Aukidy et al. 2012) y son liberados posteriormente al ambiente mediante las descargas de agua residual tratada.

Las PTAR son consideradas como puntos de acceso y selección de bacterias resistentes. Albergan una alta densidad y diversidad de bacterias ambientales asociadas con humanos y animales (incluidos los patógenos), y tienen diversos factores de resistencia a antibióticos que pueden intercambiarse entre ellas (Bengtsson-Palme et al. 2016, Manaia et al. 2018). No obstante, el efecto del tratamiento de agua residual sobre la resistencia bacteriana se ha estudiado en todo el mundo. Varios autores han investigado 
la selección de resistencia bacteriana mediante la comparación de poblaciones de bacterias en el influente y el efluente, lo que ha producido resultados variables y a veces contradictorios (Flach et al. 2018). Si bien los resultados no siempre son consistentes, se han encontrado patrones, y en algunos casos se han observado aumentos de resistencia bacteriana a múltiples antibióticos (Grabow et al. 1974, Linton et al. 1974, Mezrioui y Baleux 1994).

Es de suma importancia monitorear las PTAR debido a que el agua tratada que se descarga puede generar propagación de cepas resistentes a antibióticos de interés para las Instituciones de Salud Pública y ocasionar altas tasas de morbilidad y mortalidad para la población. Cabe mencionar que en México sólo se monitorea la calidad del agua con algunos parámetros físicos y químicos mínimos establecidos en la Norma Oficial Mexicana NOM-001-SEMARNAT-1996 (SEMARNAT 1996a); en cuanto a los parámetros biológicos, sólo se reportan coliformes fecales, totales y E. coli, pero se desconoce la presencia de los patotipos y la resistencia a antibióticos. Por ello el objetivo de esta investigación fue estudiar la prevalencia de patotipos de E. coli presentes en el agua residual resistentes a antibióticos en una PTAR al sur de México, con el fin de aportar datos sobre la misma y sugerir acciones.

\section{MATERIALES Y MÉTODOS}

\section{Sitio de estudio}

Se seleccionó una PTAR localizada en Acapulco, Guerrero, México. Esta planta trata el agua residual generada por una población estimada de $800 \mathrm{mil}$ habitantes, con una capacidad instalada de $1.35 \mathrm{~m}^{3} / \mathrm{s}$ de caudal en el efluente. El tratamiento consiste en un proceso biológico aeróbico a nivel secundario por lodos activados con desinfección por radiación UV y espesamiento mecánico, digestión aeróbica y deshidratación en filtros banda para los lodos. El tratamiento del agua residual cruda previo al biológico, consiste en la eliminación de la materia flotante, basura y sólidos gruesos por procedimientos mecánicos de desbaste grueso y fino, y la desarenación mecánica con aeración y extracción mecánica del material granular.

\section{Colección de muestra para los estudios bacterio- lógicos}

Se realizaron tres muestreos compuestos en la PTAR en diferentes momentos en enero, febrero y abril de 2018. Las muestras de agua de los diferentes procesos (influente, antes de la desinfección [AD] y después de la desinfección [DDE], y efluente) se colocaron en frascos estériles de $50 \mathrm{~mL}$. Las muestras se mantuvieron en cadena fría durante el transporte y se analizaron en el laboratorio.

\section{Análisis físicos y químicos de las muestras de agua}

En el momento de cada muestreo se registraron in situ la temperatura, el $\mathrm{pH}$ y la conductividad eléctrica (Ce). Además, se midieron los siguientes parámetros: demanda química de oxígeno (DQO), demanda bioquímica de oxígeno $\left(\mathrm{DBO}_{5}\right)$, dureza total, turbidez, sólidos suspendidos volátiles (SSV), sólidos suspendidos totales (SST), coliformes fecales, totales y $E$. coli, y se determinó el número más probable (NMP) con base en la Norma Mexicana NMX-AA-042SCFI-2015 (SE 2015a) en el laboratorio de análisis químico ambiental de la Universidad Autónoma de Guerrero, considerando las normas vigentes correspondientes (SEMARNAT 1996a, b, 1997). Con los datos obtenidos se calculó el porcentaje de eficiencia de remoción del reactor biológico (con en la $\mathrm{DBO}_{5}$ ):

$\%$ eficiencia $=\frac{D B O_{5 \text { influente }}-D B O_{5} \text { efluente }}{D B O_{5 \text { influente }}}$

donde $\%$ eficiencia es el porcentaje de eficiencia remoción de la PTAR; $D B O_{5}$ influente es el valor de la $D B O_{5}$ de la muestra del influente en $\mathrm{mg} / \mathrm{L}$; y $\mathrm{DBO}_{5}$ effuente es el valor el valor de la $\mathrm{DBO}_{5}$ de la muestra del efluente en $\mathrm{mg} / \mathrm{L}$.

\section{Aislamiento e identificación de $\boldsymbol{E}$. coli}

Para el aislamiento de E. coli en las muestras se realizaron diluciones de $10^{-1}$ a $10^{-6}$. De esta última dilución se inocularon $100 \mu \mathrm{L}$ en cajas de Petri con agar BHI y agar MacConkey por duplicado y se incubaron durante $24 \mathrm{~h}$ a $30{ }^{\circ} \mathrm{C}$.

Posteriormente se realizó el conteo del total de colonias en cada medio de cultivo y se multiplicó por la dilución correspondiente. En el agar MacConkey se seleccionaron al azar 10 colonias lactosa-positivas con morfología colonial de E. coli por muestra. Las colonias y se identificaron con el sistema API20E siguiendo el protocolo del fabricante. Todas las cepas identificadas como E. coli se conservaron en glicerol al $40 \%$ a $-70{ }^{\circ} \mathrm{C}$.

\section{Detección de patotipos en las cepas de $E$. coli por PCRm}

En las cepas de E. coli seleccionadas se realizó la extracción de ADN por el método de choque térmico como lo describen Garza-Ramos et al. (2018). Se incluyeron cepas control para el estudio de los pato- 
tipos. Todas las reacciones en cadena de polimerasa múltiplex (PCRm, por sus siglas en inglés) fueron realizadas en un termociclador Biorad Mycycler $\mathrm{TM}$, en un volumen final de $25 \mu \mathrm{L}$ con el siguiente contenido por reacción: amortiguador, $2.5 \mu \mathrm{L}$; $\mathrm{MgCl}_{2}, 2.5 \mu \mathrm{L}$; dNTP, $2.5 \mu \mathrm{L}$; oligonucleótido F, $2.0 \mu \mathrm{L}$; oligonucleótido $\mathrm{R}, 2.0 \mu \mathrm{L} ; \mathrm{H}_{2} \mathrm{O}, 3 \mu \mathrm{L}$; Taq polimerasa, $0.5 \mu \mathrm{L}$ partiendo de una concentración comercial de $5 \mathrm{U} / \mu \mathrm{L}$. Cabe mencionar que en cada mix de PCRm se incluyeron dos pares de oligonucleótidos para la amplificación de los genes específicos por patotipo, los cuales se describen en el cuadro I. Las reacciones se sometieron a un paso de desnaturalización inicial a $95{ }^{\circ} \mathrm{C}$ durante 1 min, seguido de 35 ciclos que consisten en desnaturalización a $95^{\circ} \mathrm{C}$ durante $45 \mathrm{~s}$, hibridación a $58{ }^{\circ} \mathrm{C}$ durante $1 \mathrm{~min}$, extensión a $72{ }^{\circ} \mathrm{C}$ durante 1 min y elongación final a $72^{\circ} \mathrm{C}$ durante 7 min (Omar y Barnard 2010). El control positivo contenía una mezcla de cepas de E. coli correspondiente a los seis patotipos. El control negativo contenía solo agua mili Q. Los amplificados de la PCR fueron sometidos a electroforesis en un gel de agarosa al $1 \%$ teñido con bromuro de etidio $(3 \mu \mathrm{L} / 100 \mathrm{~mL})$ a $120 \mathrm{~V}$ por $1 \mathrm{~h}$ en solución amortiguadora TAE $1 \mathrm{X}$. Posteriormente, fueron visualizados con luz UV.

\section{Detección de la resistencia antimicrobiana en las cepas de $E$. coli}

Se realizó la prueba de sensibilidad antimicrobiana utilizando el método de difusión de disco estándar en agar Müeller-Hinton (MH) según lo recomendado por el Instituto de Estándares Clínicos y de Laboratorio (CLSI 2018). Se recogieron colonias frescas (aproximadamente $18 \mathrm{~h}$ ) de placas de cultivo de agar nutritivo en tubos de ensayo que contenían $5 \mathrm{~mL}$ de solución salina estéril. La turbidez de la suspensión se ajustó a 0.5 del estándar de McFarland. Se utilizaron hisopos estériles para la dispersión de la suspensión bacteriana en cajas de Petri con agar MH. Se utilizaron los siguientes discos impregnados con antibióticos: amikacina (AK, $30 \mu \mathrm{g})$, gentamicina $(\mathrm{CN}, 10 \mu \mathrm{g})$, meropenem (ME, $10 \mu \mathrm{g}$ ), tetraciclina (TE, $30 \mu \mathrm{g}$ ), levofloxacino (LEV, $5 \mu \mathrm{g}$ ), claritromicina (CLR, $15 \mu \mathrm{g}$ ), trimetoprima/sulfametaxol (SXT 25, $\mu \mathrm{g}$ ), amoxicilina (AMC, $30 \mu \mathrm{g}$ ), ciprofloxacino (CIP, $5 \mu \mathrm{g}$ ), ceftazidima (CAZ, $30 \mu \mathrm{g}$ ), cefotaxima (CTX, $30 \mu \mathrm{g}$ ), ceftriaxona (CRO, $30 \mu \mathrm{g})$ y cloranfenicol $(\mathrm{CL}, 30 \mu \mathrm{g})$. Asimismo, se hizo el ensayo de detección de betalactamasas de espectro extendido (BLEE, por sus siglas en inglés) en las cepas que fueron resistentes a cefalosporinas de terceravgeneración por el método de doble disco. Todos los resultados se interpretaron de acuerdo con el m étodo recomendado por el CLSI (2018).

\section{RESULTADOS Y DISCUSIÓN}

En la actualidad se requieren datos más precisos acerca de cada componente de la interfaz humano-ambiente que contribuyan a la epidemiología de E. coli, ya que pueden existir reservorios

CUADRO I. GENES DE VIRULENCIA PARA LA DETECCIÓN DE PATOTIPOS DE CEPAS DE Escherichia coli AISLADOS EN LA PTAR DE ACAPULCO, GUERRERO, MÉXICO.

\begin{tabular}{|c|c|c|c|c|}
\hline $\begin{array}{l}\text { Patotipos de } \\
\text { E. coli }\end{array}$ & $\begin{array}{l}\text { Gen de } \\
\text { virulencia }\end{array}$ & $\begin{array}{l}\text { Descripción } \\
\text { del gen }\end{array}$ & $\begin{array}{l}\text { Tamaño } \\
(\mathrm{pb})\end{array}$ & Referencia \\
\hline Enterotoxigénica & st, & $\begin{array}{l}\text { Toxina termoestable } \\
\text { Toxina termolábil }\end{array}$ & $\begin{array}{l}450 \\
191\end{array}$ & (Margall et al. 1997) \\
\hline Enteropatógena & eae & $\begin{array}{l}\text { Fimbria } \\
\text { (adherencia laxa al enterocito) }\end{array}$ & 189 & (Ud-Din y Wahid 2015) \\
\hline Enterohemorrágica & $\begin{array}{l}\text { stxl } \\
\text { stx }\end{array}$ & $\begin{array}{l}\text { Citotoxinas shiga } \\
(\mathrm{Stx} 1, \mathrm{Stx} 2)\end{array}$ & $\begin{array}{l}418 \\
255\end{array}$ & (Vidal et al. 2002) \\
\hline Enteroinvasiva & ipaH & $\begin{array}{l}\text { Proteínas Ipa } \\
\text { Complejo Mxi-Spa (adhesinas } \\
\text { internalización bacteriana) }\end{array}$ & 619 & (Weiler et al. 2017) \\
\hline Adherencia difusa & $d a A$ & $\begin{array}{l}\text { Gen conservado (operón daA) que regula } \\
\text { la expresión de la adhesina F1845 }\end{array}$ & 146 & (Riveros et al. 2011) \\
\hline Enteroagregativa & $\operatorname{agg} R$ & $\begin{array}{l}\text { Gen activador transcripcional, regulador de } \\
\text { los genes que codifican para fimbrias } \\
\text { de adherencia agregativa (AAF) }\end{array}$ & 152 & (Morín et al. 2013) \\
\hline
\end{tabular}


importantes sin identificar como los efluentes de las PTAR. En este estudio se analizó una PTAR urbana cuya eficiencia de remoción es de $95.4 \%$, que es una de las plantas de tratamiento modelo con las que cuenta México. Cabe mencionar que todos los parámetros físicos y químicos evaluados en el cuadro II se encuentran dentro de los límites permisible establecidos por la NOM-001-SEMARNAT-1996 (SEMARNAT 1996a) para determinar la calidad del agua. Es importante destacar que existen pocas PTAR que cumplen con la normativa vigente (Cuadro III).

No obstante, a pesar de cumplir con la normativa nacional vigente, hay una presencia importante de coliformes fecales y totales en el efluente, la cual disminuye después de la desinfección con luz UV, como se aprecia en el cuadro III. Estos datos coinciden con investigaciones realizadas por Flach et al. (2018), quienes investigaron la presencia de E. coli en el influente y efluente en una PTAR en Suecia durante 18 meses, y observaron que el número de aislamientos era mucho mayor en el influente que en el efluente. Asimismo, Anastasi et al. (2013) describieron la sobrevivencia de cepas de E. coli aun después del proceso de desinfección con luz UV y cloración en una PTAR.

En cuanto a la presencia de E. coli, se aislaron 320 cepas y de éstas se seleccionaron al azar 57 para estudir los patotipos y la resistencia a diversos
CUADRO III. NMP DE ORGANISMOS COLIFORMES TOTALES, FECALES y Escherichia coli EN LAS DIFERENTES ETAPAS DE TRATAMIENTOS DE LA PTAR DE ACAPULCO, GUERRERO, MÉXICO.

\begin{tabular}{lccc}
\hline Muestra & $\begin{array}{c}\text { Organismos } \\
\text { coliformes } \\
\text { totales }\end{array}$ & $\begin{array}{c}\text { Organismos } \\
\text { coliformes } \\
\text { fecales }\end{array}$ & $\begin{array}{c}\text { E. coli } \\
\text { confirmativa }\end{array}$ \\
\hline INFLUENTE & $\geq 2400$ & 1100 & 160 \\
AD & 240 & 20 & 19 \\
DDE & 93 & 21 & 16 \\
EFLUENTE & 93 & 15 & 11 \\
\hline
\end{tabular}

NMP: número más probable, AD: antes de la desinfección, DDE: después de la desinfección (interpretación con base en la NOM001-SEMARNAT-1996 (SEMARNAT 1996a).

antibióticos; de ellas, 18 pertenecían al influente, 12 a la etapa previa al proceso de desinfección, 13 a la etapa posterior al proceso de desinfección y 14 al efluente.

En estudios similares se ha observado que las cepas de E. coli se encuentran presentes en todo el sistema de tratamiento de las PTAR, probablemete por mecanismos de tolerancia o resistencia a los tratamientos de desinfección empleados en los procesos de tratamiento. Asimismo, se ha reportado su capacidad de sobrevivir en ambientes estresantes y hostiles (Anastasi et al. 2013, Flach et al. 2018).

CUADRO II. PARÁMETROS FÍSICOS Y QUÍMICOS EN EL INFLUENTE Y EFLUENTE DE LA PTAR DE ACAPULCO, GUERRERO, MÉXICO.

\begin{tabular}{|c|c|c|c|c|}
\hline Parámetro & Influente compuesto & Efluente compuesto & Norma & Referencia \\
\hline $\mathrm{T}\left({ }^{\circ} \mathrm{C}\right)$ & 29.17 & 31.30 & NMX-AA-007-SCFI-2013 & (SE 2013a) \\
\hline $\mathrm{pH}$ & 6.99 & 6.55 & NMX-AA-008-SCFI-2016 & (SE 2016a) \\
\hline $\mathrm{CE}(\boldsymbol{\mu s} / \mathbf{c m})$ & 1788.33 & 490.25 & NMX-AA-093-SCFI-2000 & (SE 2016b) \\
\hline $\mathrm{DBO}_{5}(\mathrm{mg} / \mathrm{L})$ & 1625.17 & 22.56 & NMX-AA-028-SCFI-2001 & (SE 2001a) \\
\hline $\mathrm{DQO}(\mathrm{mg} / \mathrm{L})$ & 1065.76 & 51.27 & NMX-AA-030-SCFI-2012 & (SE 2012) \\
\hline S.S.V (mg/L) & 352.42 & 496.37 & NMX-AA-034-SCFI-2015 & (SE 2015b) \\
\hline S.S.T. $(\mathrm{mg} / \mathrm{L})$ & 19.08 & 26.64 & NMX-AA-034-SCFI-2015 & (SE 2015b) \\
\hline S.S. $(\mathrm{mg} / \mathrm{L})$ & 20 & 0 & NMX-AA-004-SCFI-2013 & (SE 2013b) \\
\hline M.F & Ausente & Ausente & NMX-AA-004-SCFI-2013 & (SE 2013b) \\
\hline $\mathrm{N}_{\text {total }}(\mathrm{mg} / \mathrm{L})$ & - & 10.7 & NMX-AA-026-SCFI-2010 & (SE 2010) \\
\hline $\mathrm{P}_{\text {total }}(\mathrm{mg} / \mathrm{L})$ & - & 2.56 & NMX-AA-029-SCFI-2001 & (SE 2001b) \\
\hline $\operatorname{Alc}_{\text {total }}(\mathrm{mg} / \mathrm{L})$ & 825.46 & 201.20 & NMX-AA-036-SCFI-2001 & (SE 2001c) \\
\hline Cloruros (mg/L) & 956.45 & 98.74 & NMX-AA-073-SCFI-2001 & (SE 2001d) \\
\hline Dureza total $(\mathrm{mg} / \mathrm{L})$ & 789.61 & 225.32 & NMX-AA-072-SCFI-2001 & (SE 2001e) \\
\hline Grasas y Aceites (mg/L) & - & 6.18 & NMX-AA-005-SCFI-2000 & (SE 2013c) \\
\hline $\mathrm{SO}_{4}(\mathrm{mg} / \mathrm{L})$ & 596.24 & 24.14 & NMX-AA-074-SCFI-2014 & (SE 2014) \\
\hline Turbidez (UNT) & 70 & 2 & NMX-AA-038-SCFI-2001 & (SE 2001f) \\
\hline
\end{tabular}

T: temperatura, $\mathrm{pH}$ : potencial de hidrogeno, $\mathrm{CE}$ : conductividad eléctrica, $\mathrm{DBO}_{5}$ : demanda bioquímica de oxígeno, DQO: demanda química de oxígeno, SSV: sólidos suspendidos volátiles, SST: sólidos suspendidos totales, SS: sólidos suspendidos, MF: materia fecal, $\mathrm{N}_{\text {total }}$ : nitrógeno total, $\mathrm{P}_{\text {total }}$ : fósforo total, $\mathrm{Alc}_{\text {total }}$ : alcalinidad total, $\mathrm{SO}_{4}$ : sulfatos. 
La frecuencia de patotipos de las cepas de $E$. coli en la PTAR fue de $39 \%(22 / 57)$ para EIEC, $30 \%(17 / 57)$ para ETEC y $15.5 \%(9 / 57)$ para DAEC y EPEC. En cuanto a la distribución en los sitios de muestreo, se detectó un $39 \%$ de ETEC en el influente, $50 \%$ de EIEC antes de la desinfección, $100 \%$ de EIEC después de la desinfección y un $43 \%$ de ETEC en el efluente, como se muestra en el cuadro IV.

CUADRO IV. PREVALENCIA DE PATOTIPOS Y RESISTENCIA A LOS ANTIBIÓTICOS EN CEPAS DE Escherichia coli AISLADAS EN LA PTAR DE ACAPULCO, GUERRERO, MÉXICO.

\begin{tabular}{|c|c|c|}
\hline Sitio PTAR & Patotipos (\%) & $\begin{array}{l}\text { Resistencia a } \\
\text { antibióticos (\%) }\end{array}$ \\
\hline $\begin{array}{l}\text { Influente } \\
(\mathrm{n}=18)\end{array}$ & $\begin{array}{l}\text { DAEC: } 22 \%(4), \\
\text { EIEC: } 11 \%(2), \\
\text { EPEC: } 28 \%(5), \\
\text { ETEC: } 39 \%(7)\end{array}$ & $\begin{array}{l}\text { AK: } 11 \%(2), \text { SXT: } 44 \\
\% \text { (8), CTX: } 22 \%(4), \\
\text { CRO: } 22 \% \text { (4), CL: } 11 \\
\%(2)\end{array}$ \\
\hline $\begin{array}{l}\mathrm{AD} \\
(\mathrm{n}=12)\end{array}$ & $\begin{array}{l}\text { DAEC: } 8 \%(1), \\
\text { EIEC: } \mathbf{5 0} \% \mathbf{( 6 ) ,} \\
\text { EPEC: } 8 \%(1), \\
\text { ETEC: } 33 \%(4)\end{array}$ & $\begin{array}{l}\text { SXT: } 33 \% \text {, CXT: } 42 \% \text {, } \\
\text { CXT- } \\
\text { CLA: } 25 \% \text {, MEM: } 42 \\
\% \text {, CL: } 25 \%\end{array}$ \\
\hline $\begin{array}{l}\mathrm{DDE} \\
(\mathrm{n}=13)\end{array}$ & EIEC: $100 \%(13)$ & $\begin{array}{l}\text { GN23: } \% \text {, AK: } 15 \% \text {, } \\
\text { SXT: } 31 \% \text {, CAZ: } 23 \% \text {, } \\
\text { CXT: } 31 \% \text {, CXT-CLA: } \\
15 \% \text {, MEM: } 23 \%\end{array}$ \\
\hline $\begin{array}{l}\text { Efluente } \\
(\mathrm{n}=14)\end{array}$ & $\begin{array}{l}\text { DAEC: } 27 \%(4), \\
\text { EIEC: } 7 \%(1), \\
\text { EPEC: } 21 \%(3), \\
\text { ETEC: } \mathbf{4 3 \% ( 6 )}\end{array}$ & $\begin{array}{l}\text { AMC, TE, CXT-CLA, } \\
\text { CRO, } \\
\text { MEM y CL: } 14 \% \text {, SXT: } \\
38 \% \text {, } \\
\text { CXT: } 28 \%\end{array}$ \\
\hline
\end{tabular}

AD: antes de la desinfección, DDE: después de la desinfección, DAEC: difusamente adherente, EIEC: enteroinvasiva, EPEC: enteropatogénica, ETEC: enterotoxigénica, AK: amikacina, SXT: trimetoprima/sulfametoxazol, CXT: cefotaxima, CRO: ceftriaxona, CL: cloranfenicol, GN: gentamicina, CAZ: ceftazidima, CXT-CLA: cefotaxima/ácido clavulánico, AMC: amoxacilina/ ácido clavulánico, MEM: meropenem, TE: tetraciclina.

Respecto a la sobrevivencia de cepas de E. coli, se ha reportado que $1 \times 10^{2} \mathrm{UFC} / \mathrm{mL}$ sobreviven a los tratamientos empleados para la desinfección del agua, ya que pueden tener o transferirse genes que les ayudan a sobrevivir y proliferar en ambientes acuáticos (Reinthaler et al. 2003). Asimismo, se ha demostrado la ineficiencia del tratamiento con radiación UV contra coliformes fecales, ya que las bacterias tienen la capacidad de reparar y revertir los efectos negativos sobre su ADN. Esto ocurre cuando las dosis de radiación UV son bajas y los tiempos de exposición son cortos según lo reportado por Okoh et al. (2007). Con relación a la desinfección con cloro, esta puede ser más efectiva para inactivar a las bacterias, pero se han encontrado cepas de $E$. coli que pueden sobrevivir en agua clorada. Dentro de los patotipos de E. coli que pueden resistir los procesos de desinfección en las PTAR se encuentran las uropatogénicas (UPEC), de acuerdo con estudios realizados por Anastasi et al. (2013).

Las cepas analizadas en este estudio fueron sensibles a diversos antibióticos, a saber: $93 \%$ a tetraciclina; $80 \%$ a levofloxacino, gentamicina, amoxacilina, ceftriaxona y amikacina; $77 \%$ a cloranfenicol; $68 \%$ a ceftazidima; $65 \%$ a cefotaxima, y $60 \%$ a meropenem y trimetoprima/sulfametoxazol. Ninguna tuvo la capacidad de producir BLEE. Las cepas con mayor resistencia a antibióticos se detectaron después del proceso de desinfección y en el efluente (Cuadro IV). En un estudio exhaustivo, Flach et al. (2018) detectaron la presencia de E. coli en una PTAR con mayor capacidad de tratamiento que la estudiada en esta investigación, indicando que no hay selección de resistencia bacteriana; sin embargo, se demostró la resistencia a siete antibióticos evaluados con un mismo comportamiento en el influente y el efluente, lo cual puede deberse a la presencia de trazas de antibióticos en el agua.

A pesar que se detectaron algunos antibióticos en concentraciones que pudieron haber ejercido presión selectiva sobre los perfiles de resistencia de E. coli, no se observó correlación alguna. Cabe mencionar que los resultados de Flach et al. (2018) son contradictorios con otros autores (e.g., Davies y Davies 2010). Davies y Davies (2010), mencionan que la selección de bacterias resistentes a antibióticos puede estar relacionada con la presencia de trazas de estos fármacos o metabolitos secundarios que promueven la selección de cepas resistentes, ya sea por mutaciones o por transferencia horizontal de genes de resistencia con otros microorganismos en diversos ambientes. Por ello la convivencia de cepas de E. coli con trazas de antibióticos y otros microorganismos resistentes en las PTAR conduce a la posible selección de cepas de diversos patotipos de E. coli resistentes a antibióticos, lo cual representan un peligro inminente para la salud ambiental y humana (Fig. 1).

Cabe mencionar que en el efluente se repiten los patotipos que se detectaron en el influente, prácticamente en la misma proporción (Cuadro IV), por lo tanto, los procesos de desinfección no son efectivos con relación a estas bacterias y la remoción de antibióticos es baja o nula en esta PTAR. Los datos 


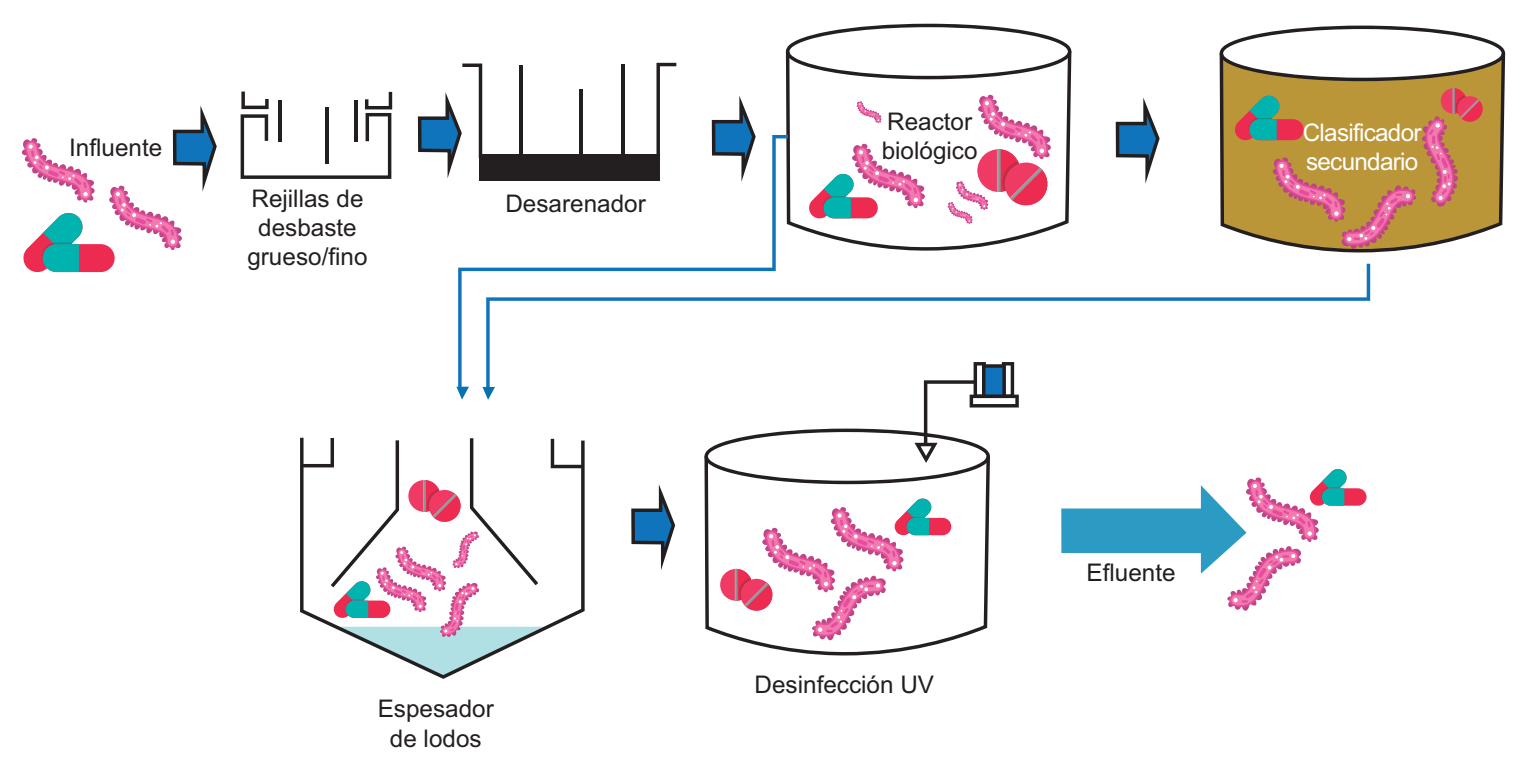

Fig. 1. Diagrama de flujo de la presencia de patotipos y selección de cepas resistentes de Escherichia coli en todos los procesos de tratamiento del agua en la PTAR de Acapulco, Guerrero, México.

observados en esta investigación indican que las bacterias patógenas no se remueven en su totalidad, por lo que deben diseñarse estrategias de remoción para eliminarlas o retenerlas dentro del sistema de tratamiento. Además, se sugiere evaluar el tratamiento de fotocatálisis heterogénea $\mathrm{TiO}_{2}$ propuesto por Rojas-Higuera et al. (2010) como un método eficaz para la remoción de coliformes y E. coli en agua residual.

La importancia de monitorear las PTAR continuamente radica en que el agua tratada podría reutilizarse para actividades domésticas (e.g., riego de áreas verdes, entre otras), además de aprovecharse para labores agrícolas; sin embargo, esto podría conducir a la dispersión de cepas potencialmente patógenas en el ambiente. La eficiencia de las PTAR se ha minimizado a conocer los parámetros físicos, químicos y bacteriológicos, sin considerar la presencia de patotipos resistentes a antibióticos en cepas de E. coli, que aumentan la morbilidad/mortalidad y ocasionan la disminución de los tratamientos disponibles y el control de casos.

\section{CONCLUSIÓN}

Los resultados demuestran la persistencia de patotipos diarreicos en las cepas de $E$. coli y su resistencia a ciertos antibióticos en los diferentes procesos de tratamiento de las PTAR. Por ello es necesario evaluar procesos adicionales que tengan la capacidad de eliminar este tipo de bacterias presentes en el agua residual tratada, con el fin de evitar el desequilibrio en el medio acuático y afectaciones a la salud humana y el ambiente.

\section{AGRADECIMIENTOS}

Queremos agradecer a Enrique Jesús Munguía Flores por su apoyo en el muestreo y procesamiento de las muestras de este proyecto.

\section{REFERENCIAS}

Al Aukidy M., Verlicchi P., Jelic A., Petrovic M. y Barceló D. (2012). Monitoring release of pharmaceutical compounds: Occurrence and environmental risk assessment of two WWTP effluents and their receiving bodies in the Po Valley, Italy. Sci. Total Environ. 438, 15-25. https://doi.org/10.1016/j.scitotenv.2012.08.061

Anastasi E.M., Wohlsen T.D., Stratton H.M. y Katouli M. (2013). Survival of Escherichia coli in two sewage treatment plants using UV irradiation and chlorination for disinfection. Water Res. 47 (17), 6670-6679. https:// doi.org/10.1016/j.watres.2013.09.008 
Bengtsson-Palme J., Hammarén R., Pal, C., Östman M., Björlenius B., Flach C.F. y Larsson D.J. (2016). Elucidating selection processes for antibiotic resistance in sewage treatment plants using metagenomics. Sci. Total Environ. 572, 697-712. https://doi.org/10.1016/j. scitotenv.2016.06.228

Chow L., Waldron L. y Gillings M. (2015). Potential impacts of aquatic pollutants: subclinical antibiotic concentrations induce genome changes and promote antibiotic resistance. Front. Microbiol. 6, 803. https:// doi.org/10.3389/fmicb.2015.00803

CLSI (2018). Performance standards for antimicrobial susceptibility testing. 28th ed. Supplement M100. Clinical and Laboratory Standards Institute, Wayne, PA, EUA, 296 pp.

Davies J. y Davies D. (2010). Origins and evolution of antibiotic resistance. Microbiol. Mol. Biol. R. 74 (3), 417-433. https://doi.org/10.1128/MMBR.00016-10

Flach C.F., Genheden M., Fick J. y Joakim-Larsson D.G. (2018). A comprehensive screening of Escherichia coli isolates from Scandinavia's largest sewage treatment plant indicates no selection for antibiotic resistance. Environ. Sci. Technol. 52 (19), 11419-11428. https:// doi.org/10.1021/acs.est.8b03354

Franzolin M.R., Alves R.C., Keller R., Gomes T.A., Beutin L., Barreto M., Milroy C., Strina A., Ribeiro H. y Trabulsi L. (2005). Prevalence of diarrheagenic Escherichia coli in children with diarrhea in Salvador, Bahia, Brazil. Mem. I. Oswaldo Cruz. 100 (4), 359-363. https://doi.org/10.1590/S007402762005000400004

Garza-Ramos U., Barrios-Camacho H., MorenoDomínguez S., Toribio-Jiménez J., Jardón-Pineda D., Cuevas-Peña J., Sánchez-Pérez A., Durán-Bedolla J., Olguín-Rodríguez J. y Román-Román A. (2018). Phenotypic and molecular characterization of Klebsiella $s p p$. isolates causing community-acquired infections. New Microbes New Infect. 23, 17-27 https://doi. org/10.1016/j.nmni.2018.02.002

Grabow W.O.K., Prozesky O.W. y Smith L.S. (1974). Drug resistant coliforms call for review of water quality standards. Water Res. 8 (1), 1-9. https://doi. org/10.1016/0043-1354(74)90002-5

Gullberg E., Cao S., Berg O.G., Ilbäck C., Sandegren L., Hughes D. y Andersson D.I. (2011). Selection of resistant bacteria at very low antibiotic concentrations. PLOS Pathog. 7 (7). https://doi.org/10.1371/journal. ppat. 1002158

Huang D.B., Mohanty A., DuPont H.L., Okhuysen P.C. y Chiang T. (2006). A review of an emerging enteric pathogen: Enteroaggregative Escherichia coli. J. Med. Microbiol. 55 (10), 1303-1311. https://doi.org/10.1099/ jmm.0.46674-0
Kasprzyk-Hordern B., Dinsdale R.M. y Guwy A.J. (2008). The occurrence of pharmaceuticals, personal care products, endocrine disruptors and illicit drugs in surface water in South Wales, UK. Water Res. 42 (13), 34983518. https://doi.org/10.1016/j.watres.2008.04.026

Kümmerer K. (2009a). Antibiotics in the aquatic environment-A review - Part I. Chemosphere 75 (4), 417-434. https://doi.org/10.1016/j.chemosphere.2008.11.086

Kümmerer K. (2009b). Antibiotics in the aquatic environment - A review - Part II. Chemosphere 75 (4), 435-441. https://doi.org/10.1016/j.chemosphere.2008.12.006

Linton K.B., Richmond M.H., Bevan R. y Gillespie W.A. (1974). Antibiotic resistance and $\mathrm{R}$ factors in coliform bacilli isolated from hospital and domestic sewage. J. Med. Microbiol. 7 (1), 91-103. https://doi. org/10.1099/00222615-7-1-91

Manaia C.M., Rocha J., Scaccia N., Marano R., Radu E., Biancullo F., Cerqueira F., Fortunato G., Iakovides I., Kampouris I., Vaz-Moreira I. y Nunes O. (2018). Antibiotic resistance in wastewater treatment plants: Tackling the black box. Environ. Int. 115, 312-324. https://doi.org/10.1016/j.envint.2018.03.044

Margall N., Domínguez À., Prats G. y Salleras L. (1997). Escherichia coli enterohemorrágica. Rev. Esp. Salud Públic. 71 (5), 437-443.

Martí E., Variatza E. y Balcázar J.L. (2014). The role of aquatic ecosystems as reservoirs of antibiotic resistance. Trends Microbiol. 22 (1), 36-41. https://doi. org/10.1016/j.tim.2013.11.001

Mezrioui N. y Baleux B. (1994). Resistance patterns of $E$. coli strains isolated from domestic sewage before and after treatment in both aerobic lagoon and activated sludge. Water Res. 28 (11), 2399-2406. https://doi. org/10.1016/0043-1354(94)90056-6

Morín N., Santiago A.E., Ernst R.K., Guillot S.J. y Nataro J.P. (2013). Characterization of the AggR regulon in enteroaggregative Escherichia coli. Infect. Immun. 81 (1), 122-132. https://doi.org/10.1128/ IAI.00676-12

Nataro J.P. y Kaper J.B. (1998). Diarrheagenic Escherichia coli. Clin. Microbiol. Rev. 11 (1), 142-201. https://doi. org/10.1128/CMR.11.1.142

Novo A., André S, Viana P., Nunes O.C. y Manaia C.M. (2013). Antibiotic resistance, antimicrobial residue and bacterial community composition in urban wastewater. Water Res. 47, 1875-1887. https://doi.org/10.1016/j. watres.2013.01.010

Okoh A.I., Odjadjare E.E., Igbinosa E.O. y Osode A.N. (2007). Wastewater treatment plants as a source of microbial pathogens in receiving watersheds. Afr. J. Biotechnol. 6 (25), 2932-2944. https://doi.org/10.5897/ AJB2007.000-2462 
Omar K.B. y Barnard T.G. (2010). The occurrence of pathogenic Escherichia coli in South African wastewater treatment plants as detected by multiplex PCR. Water SA, 36 (2), 172-176. https://doi.org/10.4314/ wsa.v36i2.183725

Reinthaler F.F., Posch J., Feierl G., Wüst G., Haas D., Ruckenbauer G. y Marth E. (2003). Antibiotic resistance of $E$. coli in sewage and sludge. Water Res. 37 (8), 1685-1690. https://doi.org/10.1016/S00431354(02)00569-9

Riveros M., Barletta F., Cabello M., Durand D., Mercado E.H., Contreras C., Rivera F.P., Mosquito S., Lluque A. y Ochoa T.J. (2011). Adhesion patterns in diffusely adherent Escherichia coli (DAEC) strains isolated from children with and without diarrea. Revista Peruana de Medicina Experimental y Salud Pública 28 (1):21-8. https://doi.org/10.1590/s1726-46342011000100004

Rodríguez C., Lang L., Wang A., Altendorf K., García F. y Lipski A. (2006). Lettuce for human consumption collected in Costa Rica contains complex communities of culturable oxytetracycline-and gentamicin-resistant bacteria. Appl. Environ. Microb. 72 (9), 5870-5876. https://doi.org/10.1128/AEM.00963-06

Rojas-Higuera N., Sánchez-Garibello A., Matiz-Villamil A., Salcedo-Reyes J.C., Carrascal-Camacho A.K. y Pedroza-Rodríguez A.M. (2010). Evaluación de tres métodos para la inactivación de coliformes y Escherichia coli presentes en agua residual doméstica, empleada para riego. Universitas Scientiarum 15 (2): 139-149.

SE (2001a). Norma Mexicana NMX-AA-028-SCFI-2001. Análisis de agua-Determinación de la demanda bioquímica de oxígeno en aguas naturales, residuales $\left(\mathrm{DBO}_{5}\right)$ y residuales tratadas.-Método de prueba. Dirección General de Normas, Secretaría de Economía. Diario Oficial de la Federación, 17 de abril.

SE (2001b). Norma Mexicana NMX-AA-029-SCFI-2001 Análisis de aguas-Determinación de fósforo total en aguas naturales, residuales y residuales tratadas.- Método de prueba. Dirección General de Normas, Secretaría de Economía. Diario Oficial de la Federación, 17 de abril.

SE (2001c). Norma Mexicana NMX-AA-036-SCFI-2001. Análisis de agua-Determinación de acidez y alcalinidad en aguas naturales, residuales y residuales tratadas.Método de prueba. Dirección General de Normas, Secretaría de Economía. Diario Oficial de la Federación, 1 de agosto.

SE (2001d). Norma Mexicana NMX-AA-073-SCFI-2001. Análisis de agua-Determinación de cloruros totales en aguas naturales, residuales y residuales tratadas.Método de prueba Dirección General de Normas, Secretaría de Economía. Diario Oficial de la Federación, 13 de agosto.
SE (2001e). Norma Mexicana NMX-AA-072-SCFI-2001 Análisis de agua-Determinación de dureza total en aguas naturales, residuales y residuales tratadas.Método de prueba. Dirección General de Normas, Secretaría de Economía. Diario Oficial de la Federación, 13 de agosto.

SE (2001f). Norma Mexicana NMX-AA-038-SCFI-2001. Análisis de agua-Determinación de turbiedad en aguas naturales, residuales y residuales tratadas.- Método de prueba Dirección General de Normas, Secretaría de Economía. Diario Oficial de la Federación, 1 de agosto. SE (2010). Norma Mexicana NMX-AA-026-SCFI-2010 Análisis de agua-Medición de nitrógeno total kjeldahl en aguas naturales, residuales y residuales tratadas.Método de prueba. Dirección General de Normas, Secretaría de Economía. Diario Oficial de la Federación, 3 de marzo.

SE (2012). Norma Mexicana NMX-AA-030/1-SCFI-2012 Análisis de agua-Medición de la demanda química de oxígeno en aguas naturales, residuales y residuales tratadas.-Método de prueba. Parte 1- Método de reflujo abierto. Dirección General de Normas, Secretaría de Economía. Diario Oficial de la Federación, 21 de mayo.

SE (2013a). Norma Mexicana NMX-AA-007-SCFI-2013 Análisis de agua- Medición de la temperatura en aguas naturales, residuales y residuales tratadas-Método de prueba. Dirección General de Normas, Secretaría de Economía. Diario Oficial de la Federación, 23 de enero. SE (2013b). Norma Mexicana NMX-AA-004-SCFI-2013. Análisis de agua-Medición de sólidos sedimentables en aguas naturales, residuales y residuales tratadas.Método de prueba. Dirección General de Normas, Secretaría de Economía. Diario Oficial de la Federación, 13 de noviembre.

SE (2013c). Norma Mexicana NMX-AA-005-SCFI-2013. Análisis de agua-Medición de grasas y aceites recuperables en aguas naturales, residuales y residuales tratadas-Método de prueba. Dirección General de Normas, Secretaría de Economía. Diario Oficial de la Federación, 11 de abril.

SE (2014). Norma Mexicana NMX-AA-074-2014 Análisis de agua-Medición del ión sulfato en aguas naturales, residuales y residuales tratadas-Método de prueba. Dirección General de Normas, Secretaría de Economía. Diario Oficial de la Federación, 25 de agosto.

SE (2015a). Norma Mexicana NMX-AA-042-SCFI-2015. Enumeración de Organismos Coliformes Totales, organismos coliformes Fecales (termotolerantes) y Escherichia coli-Método del número más probable en tubos múltiples. Secretaría de Economía. Diario Oficial de la Federación, 18 de abril.

SE (2015b). Norma Mexicana NMX-AA-034-SCFI-2015 Análisis de agua-Medición de sólidos y sales disueltas 
en aguas naturales, residuales y residuales tratadasMétodo de prueba. Dirección General de Normas, Secretaría de Economía. Diario Oficial de la Federación, 18 de abril.

SE (2016a). Norma Mexicana NMX-AA-008-SCFI-2016. Análisis de agua-Medición de $\mathrm{pH}$ en aguas naturales, residuales y residuales tratadas-Método de prueba. Dirección General de Normas, Secretaría de Economía. Diario Oficial de la Federación, 25 de agosto de 2016. SE (2016b). Norma Mexicana NMX-AA-093-SCFI-2000. Análisis de agua-Determinación de la conductividad electrolítica.-Método de prueba. Dirección General de Normas, Secretaría de Economía. Diario Oficial de la Federación, 25 de agosto.

SEMARNAT (1996a). Norma Oficial Mexicana NOM001-SEMARNAT-1996. Que establece los límites máximos permisibles de contaminantes en las descargas de aguas residuales en aguas y bienes nacionales. Secretaría de Medio Ambiente y Recursos Naturales. Diario Oficial de la Federación, 3 de junio.

SEMARNAT (1996b). Norma Oficial Mexicana NOM002-SEMARNAT-1996. Que establece los límites máximos permisibles de contaminantes en las descargas de aguas residuales a los sistemas de alcantarillado urbano o municipal. Secretaría de Medio Ambiente y Recursos Naturales. Diario Oficial de la Federación, 3 de junio.

SEMARNAT (1997). Norma Oficial Mexicana NOM003-SEMARNAT-1997. Que establece los límites máximos permisibles de contaminantes para las aguas residuales tratadas que se reúsen en servicios al público. Secretaría de Medio Ambiente y Recursos Naturales. Diario Oficial de la Federación, 21 de septiembre.

Shaheen H.I., Khalil S.B., Rao M.R., Elyazeed R.A., Wierzba T.F., Peruski L.F., Putman S., Navarro A., Morsy B., Cravioto A., Clemens J., Svennerholm A. y Savarino S. (2004). Phenotypic profiles of enterotoxigenic Escherichia coli associated with early childhood diarrhea in rural Egypt. J. Clin. Microbiol. 42 (12), 5588-5595. https://doi.org/10.1128/JCM.42.12.55885595.2004

Sidhu J.P. y Toze S.G. (2009). Human pathogens and their indicators in biosolids: A literature review. Environ Int. 35 (1), 187-201. https://doi.org/10.1016/j. envint.2008.07.006

Ud-Din A. y Wahid S. (2014). Relationship among Shigella spp. and enteroinvasive Escherichia coli (EIEC) and their differentiation. Braz. J. Microbiol. 45 (4), 1131-1138. https://doi.org/10.1590/S151783822014000400002

US-EPA (2005). Method 1623. Cryptosporidium and Giardia in water by filtration/IMS/IFA. Manual. Office of Ground Water and Drinking Water, United States Environmental Protection Agency. Cincinnati, OH, EUA, 68 pp.

Vidal M., Carreño M., Vidal R., Arellano C., Solari V. y Prado V. (2002). Evaluación de técnicas moleculares e inmunoenzimáticas para la detección de E coli enterohemorrágico en brotes de toxiinfecciones alimentarias. Rev. Med. Chile 130 (6), 603-609. https://doi. org/10.4067/S0034-98872002000600001

Weintraub A. (2007). Enteroaggregative Escherichia coli: Epidemiology, virulence and detection. J. Med. Microbiol. 56 (1), 4-8. https://doi.org/10.1099/ jmm.0.46930-0

Weiler N., Orrego M., Álvarez M. y Huber C. (2017). Detección molecular de Escherichia coli diarreogénicas en pacientes pediátricos con síndrome diarreico agudo en Paraguay. Memorias del Instituto de Investigaciones en Ciencias de la Salud 15 (1): 16-21. https://doi. org/10.18004/Mem.iics/1812-9528/2017.015(01)16021

Ye L. y Zhang T. (2011). Pathogenic bacteria in sewage treatment plants as revealed by pyrosequencing. Environ. Sci. Technol. 45 (17), 7173-7179. https://doi. org/10.1021/es201045e 